\title{
Stakeholder Power in E-business Adoption with a Game Theory Perspective
}

\author{
Barbara Roberts ${ }^{1}$ \\ ${ }^{1}$ University of South Australia, Marketing and Development Unit, Barbara.Roberts@unisa.edu.au \\ Received 7 February 2008; received in revised form 7 August 2008; accepted 5 January 2009
}

\begin{abstract}
The likelihood that one organization can pressure the e-business adoption practices of other organizations depends on two conditions: there must be sufficient power difference between the organizations; and the ebusiness process benefit must be sensitive to the number of adopters. Given these two conditions, the powerful organization can use their power advantage to control adopter numbers through urging or suppressing adoption by others. Examples from practice are provided, a theoretical framework capturing the three dimensional nature of e-business adoption influence is developed, and Game Theory is used to explore the range of possible outcomes when pressure to adopt is brought to bear between organizations of unequal power.
\end{abstract}

Key words: Stakeholder relationships, e-business adoption, Stakeholder relationships, e-business adoption, Power relationships, Game Theory, Power relationships, Game Theory, e-Government 


\section{Introduction}

Organizational stakeholder power, the ability of one interested organization to influence the behaviour of another organization, emerged as an important explanatory factor during empirical research conducted in 2003 into the nature and extent of internet-based e-business adoption by Australian wineries. This research produced a rich source of both qualitative and quantitative empirical data to help understand and explain the complex set of drivers and barriers the wineries deal with when deciding which e-business processes to adopt. The role of stakeholder power, used in some situations as an adoption driver and in other cases as an adoption barrier, is examined with examples from the Australian wine industry provided as support. This research was motivated by the observation that some e-business adoption by Australian wineries occurs despite no direct benefit or noticeable relative advantage being perceived by the wineries, and sometimes occurs despite there being no spare resource capacity. In the absence of the normally accepted adoption motivator of sufficient perceived intrinsic relative advantage, why then would organizations go to the cost and effort of adopting e-business processes? One explanation is that some adoption occurs as a result of pressure from a more powerful external stakeholder organization concerned with the stakeholder's own benefit. Whether or not an external stakeholder can readily exert pressure on other supply chain organizations to adopt e-business processes is determined by the relative power differences: in general, organizations with greater power are more able to urge or mandate adoption behaviour as a result of their power advantage.

Governments and big businesses are two stakeholders with more power than most: both drive and shape economies and the industries/communities in which the economies operate. In particular, governments are dominant stakeholders due to their legislative and regulatory power and as the provider of critical ICT network infrastructure. However, powerful organizations are selective in exerting their power because of related costs. I argue that the likelihood of a more powerful organization choosing to influence e-business adoption by others rises when either the increase or suppression of adopter numbers significantly alters the degree of benefit delivered to the more powerful organization. If a government views there is sufficient advantage in a particular e-business process being adopted by all users, then they can effectively mandate its adoption. Organizations have little choice but to comply with government regulations if they wish to continue the same operations. An example of government-mandated ebusiness adoption in Australia is provided later. Likewise, organizations sometimes have little choice but to follow the directions of more powerful supply chain organizations, such as key customers or suppliers, if the more powerful organization requires particular e-business processes to be adopted (or not) in order to increase their own benefit. Research into e-business adoption by Australian wineries is used to explore the role of stakeholder power in ebusiness adoption practice.

A literature review focusing on organizational influence on e-business adoption is presented next as background material. This is followed by discussion of the research into e-business adoption by Australian wineries, covering methodology, data analysis, and the findings in relation to the influence of external organizations, particularly those organizations with greater power than the wineries. A theoretical framework is then developed which explores the relationship between e-business benefits, the ability to control the number of organizations adopting selected ebusiness processes, and power differences between stakeholders. Comparison and analogies with decision-making processes in rule-based games are included as they help to understand and explore the range of choices between possible actions that organizations face when it comes to adoption decisions. Finally, various possible adoption outcomes are explored from a Game Theory perspective.

\section{Literature Review}

Power, as a concept, describes the situation where an individual or group can influence the behaviour of other(s), and organization power specifically applies when "organizations do things as a consequence of decisions to act in certain ways by certain other agents" [1], p. 197. The decision to exercise power involves an intention to generate particular outcomes, usually via the application of rules or guidelines designed to control for desired outcomes [1]. The ability to exert power is made easier when the levels of power between organizations are unequal, as suggested by the classic quotation that "He who has the gold, makes the rules" [1], p. 210. Thus organizational power is related to economic performance within the market place. Successful economic performance has long been empowered and enabled by technological advances, and the adoption of information and communication technologies in recent years underpins much of the recent economic growth [2]. In particular, efficiency gains from technological progress and improved business information from increased data processing power is a critical driver for modern organizations to achieve competitive advantage [3].

The study of how power and rules influence outcomes in strategic games is a useful mechanism for analyzing these same forces within business contexts due to the similarities between the two environments, recognizing that these forces act in a much less clearly defined manner within most business contexts [1], [4]. Parallels between business and games exist because of the component similarity: both have players, rules, tactics, and interactions between players. Indeed, game terminology is often used in business analysis, as the following quotation demonstrates: "Successful business strategy is about actively shaping the game you play, not just playing the game you find" [4], 
p. 59. Game Theory particularly aids the strategic decision making process in situations where the actions of others are considered either before or as part of one's own actions are decided upon [2]. Thus speculative exploration of Game Theory is relevant in this research as it takes into account the interdependencies between organizations and helps explain the empirical evidence from organizations that "need to acknowledge powerful stakeholders and act to take account of their needs and expectations" [5], p. 45.

Governments are increasingly adopting e-business processes in order to enhance the delivery of government services or to help manage compliance with government regulations [6]-[8], and the term e-government is used to distinguish between public sector e-business activity and that generated by the private sector. The major motivations for governments to adopt e-business processes are the same as that of businesses: to realize the benefits of transaction cost reduction and improvement of information flow and service delivery for the good of the government, its citizens, and the national economy [7], [9], [10]. Many governments now actively champion e-business adoption by their citizenry due to the significant advantages they believe follow from the growing economies of scale [11], greater global penetration and increased efficiencies and productive capacity related to use of ICT based business processes. Also there is increasing demand for the delivery of online government services from the citizens themselves in order to improve timely access to information and services [12]-[14], so both the demand for and supply of online government services act as complementary drivers of increased adoption.

Customer power is acknowledged as having particular influence on e-business adoption in the B2B sector [15, 16]. Large significant customers have the power to pressure adoption of e-business practices by their suppliers in order to streamline processes, reduce transaction costs, and improve efficiency through online communication and order taking [16]. Research into e-business adoption in Taiwan, for example, found competitive pressure from other companies was a very significant influential factor on adoption [17]. A cross-country study involving ten countries which investigated the environment and policy factors shaping global e-business diffusion found that B2B activity was largely driven by global competitive forces and the actions of multi-national corporations forcing local businesses to adopt e-business processes in order to stay competitive [10], [17], [18]. B2C activity appears to be largely driven by local consumer markets, with national and regional differences in markets and distribution systems resulting in considerable diversity of outcomes [17], [18].

The identification of customer power as one of the drivers of e-business adoption is supported by research into the variety of different power regimes that exist in buyer-seller relationships [19], [20]. Cox [19] found that buyer behaviour is largely determined by the buyer's power and leverage circumstances, and that the range of existing buyer-seller relationship types can be explained by the respective levels of power within the relationships and the types of markets in which the organizations operate. Buyer-seller relationships range from having low levels of commitment and operating at arm's length to relationships involving high levels of collaboration and commitment in which the buyer strives to manage the supply chain for their own advantage. However, the buyer can only attain a high level of influence over the supply chain if they also have a corresponding high level of dominance over the suppliers; the relationship is characterized not so much by equality or high levels of trust but rather by "naked (if obfuscated) power" [19], p. 348.

\section{Materials and Methodology}

The empirical data supporting this discussion of stakeholder power influence on e business adoption was generated during a study of the nature and extent of e-business adoption by Australian wineries carried out in 2003 and 2004. Australian wineries provide a suitable unit of analysis for e-business adoption for many reasons: they vary greatly in size and customer type, with customers ranging from individual consumers to very large powerful retailers; wineries compete in both international and domestic markets; they are involved in a wide range of activities and processes, ranging from the primary agricultural stage of grape growing and the secondary manufacturing stage of wine making to the tertiary stage of marketing and sales with the result that the potential for e-business process adoption is high. Also wineries are situated in both city and regional locations, allowing for network infrastructure differences to be compared. The wine industry is also highly regulated: for example, the integrity of wine labeling and the quality of wine exports is subject to specific industry regulation administered by the Australian Wine and Brandy Corporation (AWBC), a statutory body responsible to the Australian Government's Minister for Agriculture, Fisheries and Forestry [21]. For those interested, a flow chart of the structure of wine industry organizations is Available: online [22].

The organization size of wineries is traditionally judged by the annual tonnage of grapes processed rather than by the number of employees. The size range varies enormously from micro wineries processing less than 20 tonnes each year up to the very large wine companies which process at least 10000 tonnes, with the top five dominant companies processing much larger quantities. For example, in 2002 BRL Hardy processed over 270000 tonnes while Orlando Wyndham processed over 160000 tonnes [23]. For the purpose of this research the micro size wineries were not included due to their extremely limited operations. In 2003, when this research was conducted, there were 1065 wine companies processing more than 20 tonnes per year listed in the ANZ Wine Industry Directory [23]. Of these, the 26 companies that fall into the very large category processing more than 10000 tonnes a year accounted for more than $90 \%$ of total sales of Australian wine [24]. 


\subsection{Qualitative Study Evidence of External Stakeholder Pressure}

A qualitative study consisting of interviews with knowledgeable representatives from nine wineries was conducted first in order to determine which factors emerged as the most dominant or influential drivers of e-business adoption. The interviews followed a semi-structured order to ensure the same areas of e-business were covered with each winery representative, although not all types of e-business were common to all nine wineries. The major areas of ebusiness discussed in the interviews were: use of e-mail; use of web sites operated by external organizations such as government departments, industry bodies, and other commercial organizations; and the web site(s) operated by the winery. All nine wineries had a B2C public web site, the five larger wineries had an intranet, and four had an extranet site, largely used for delivery of product information to retailers and distributors. The wineries represented a broad range of company structure, size and position within the industry, and all were involved with exporting wine. While the wineries cannot be identified, two of them ranked in the top five Australian wine companies and a further three ranked in the top twenty. The smallest winery processed in the range of 100-249 tonnes annually, whereas the other three wineries processed less than 10000 tonnes annually. Employee numbers between the nine wineries ranged from 12 to over 2000 , illustrating a huge variance in size and capacity.

A cross-case analysis of the interview data revealed that influence from powerful stakeholder organizations such as business customers and the Australian Government manifested itself in winery e-business adoption behaviour in a variety of ways. Four examples of this type of influence are now presented.

\subsubsection{E-government Activity Helps to Drive the Winery's Use of External Web Sites}

Winery staff reported frequent use of government web sites. Winery staff access government sites regularly for information on government legislation and regulation for a wide range of issues such as workplace occupational health and safety, environmental protection authority reporting, taxation, and to use the online process for obtaining wine export approvals. The provision of government information via the web is viewed favorably because it increases the timeliness and ease of access and thereby increases efficiency. Six of the qualitative study wineries also used the AWBC's online process for gaining wine export approvals, with the following comment from a small regional winery representative illustrating the perceived benefit of the adoption:

"wine export approvals - my brother now uses the Internet to do all that. There are all the application forms on the Internet, so he can do all of that via the net, so he doesn't have to talk to anybody and he gets the results back over the internet or by email...we are just about to put in some workplace agreements, so I have been to the web-sites to check that out...and we have to find the current wages for all the wages people, so we use those web-sites to access that. We use the liquor licensing, we get all the permits and stuff for that...that's really good - there are lots of government web-sites that we use."

\subsubsection{E-government Activity Potential to Dictate E-business Process Adoption for Compliance Purposes}

Interviewees from the larger wineries made it clear that the Australian Custom Service was forcing adoption of an online compliance process for exports. Awareness of the impending rollout of the Australian Government's Integrated Cargo System (ICS) developed by the Australian Customs service to process export declarations, although confined to the larger wineries at the time of the interviews, revealed awareness that the government can effectively force some of the winery's e-business adoption decisions. The following interview comment illustrates the lack of choice related to processing future export clearances online, and shows that the organizations incur sizeable costs as a result:

"Australian Customs Service are putting in this new export cargo tracking system which is why we have had to spend another \$40,000 to work with this one, and we have to do it, it is compulsory, and we have to have it in by November this year."

The comments indicate that the wineries felt a much higher level of pressure from government to adopt online compliance processes for exports than for wine export approvals, indicating the government is selective when it comes to applying pressure to adopt.

\subsubsection{Powerful Business Customers can Inhibit E-business Adoption by Others}

Powerful business customers, in particular the large Australian grocery chains of Coles and Woolworths, suppress the use of the web for online sales by wineries in order to increase their own competitive advantage. All nine qualitative study wineries have their own B2C public web site for marketing and promotional purposes, with the larger wineries managing multiple brand-specific sites. Seven of the nine wineries do not use the web for online sales with the reason given that to do so would cause undesirable conflict with major business customers. Comments from winery representatives serve to illustrate this point, with the first observation coming from the largest winery representative:

"We very specifically shy away from online ordering. We believe selling online creates dangerous conflicts with our key trading partners, so our position is one of no direct sales other than through cellar doors". 
The next extract, from a medium-sized winery representative, shows that the concern about conflict with existing business customers is directly related to the existing distribution and sales channels:

"Well if we take an order off the consumer, we are actually undermining all the distribution channels out there, and as for the little retailer around the corner, what are we doing for him? We are actually taking business away from him aren't we? Well it's a little bit different for some of the smaller wineries who don't distribute out through retail outlets, etc. They have a small cellar door, they just about sell everything that they make, and the Internet is just an extension of their cellar door. It's a different distribution chain."

Thus powerful buyers appear to have sufficient power to influence the online sales strategy of their suppliers by suppressing adoption that results in direct competition. While the size (and subsequent power) of the business customer has some correspondence to the winery's size and related output, the pressure exerted by business customers appeared to be felt by the relatively smaller wineries as well. The following comment, from the representative of a winery processing less than 5000 tonnes each year, illustrates that even relatively small organizations feel that their business customers have a power advantage over them and are willing to use that power for their own advantage:

"We've got to take retail investments in us seriously, and if direct sales we made become anything high, or more importantly, noticeable, then retailers will bypass us. So that forms our position I guess of not selling online...30\%$40 \%$ of business wineries are sold through Coles and Woolworths, and there are 1000 wineries all struggling because of that. If you decide to sell direct they will cut you out, and you better be committed to sell direct for ever." Of the two qualitative study wineries who offered online sales through their B2C web site, both sold the wine at the full retail price as a way of minimizing conflict with existing distributors and retailers.

\subsubsection{Powerful Business Customers can Promote E-business Adoption by Others}

Powerful business customers such as Coles and Woolworths pressure wineries to adopt EANnet as an efficient mechanism of supplying their wine product data in order for the customers to reduce their own costs in acquiring this data.

"EANnet is mainly going to be used for the winery's communication with bigger stores like Coles, Woolworths so that they can get all of the product information, pricing, packaging, size \& weight, a whole stack of information for their use in store so using this they will design how they are going to lay it out in the store, and how much gap they need between each bottle if they want to stack them all and that sort of things. So everything to do with the product is stored on this system, that's probably the biggest way that we will be using the internet for a e-commerce type situation where we are passing data to our customers".

EANnet provides data synchronization and product registry services with the aim of allowing trading partners to synchronize their master data with the high levels of information integrity necessary for e-business with the aim of removing unnecessary costs and inefficiencies in the supply chain [25]. The following comment from another interview illustrates that wineries are responding to this pressure because they recognize that they must make it easy for major customers to do business with them, even if the relative advantage of the adoption lies largely with improving transactional efficiency and accuracy for the customers:

"Developing the software - there is a lot of time in that, the other place you get caught out like with the EANnet we are required to use some type of system to give EANnet the data, and we have like a minimum $\$ 15,000$ purchase, anywhere up to $\$ 30,000$, if we want it to be useful, so every time something like that comes along we have to make a capital purchase just to make it work, and for no real benefit for us."

\subsection{Quantitative Study Evidence of External Stakeholder Pressure}

The next stage of the research used the survey technique to collect a rich set of quantitative data in order to better describe the nature and extent of e-business adoption across Australian wineries, and explore in greater depth the role of four factors which emerged from the qualitative study and literature findings as having explanatory relevance. Four factors related to adoption of e-business were singled out for particular attention: 1) the relative advantage perceived; 2) the resource capacity to adopt; 3) pressure from business organizations within the winery supply chain; and 4) pressure from government to use online e-government services and processes. These factors were singled out after consideration of findings from both the literature review and the qualitative stage of the study: the first two factors emerge from the literature as dominant factors in explaining adoption behaviour, while the remaining two factors emerged as important factors which sometimes appeared to counter the influence of the first two factors, and thus the combination of the four factors provided an interesting study.

A census survey, sent to the CEO's of all the 1065 Australian wineries processing over 20 tonnes annually, used a highly customised mail questionnaire designed specifically for wineries. Briefly, the survey was designed to gather quantitative data on which e-business processes were being used by each winery in the domains of e-mail, use of web sites including sites operated by external organizations (external sites), and also use of winery sites (B2C, 
intranet and extranet), and on e-business in general. A section covering potential barriers to adoption was also included. Feedback on the role of the four factors was sought by seeking the level of agreement to two statements related to each factor for each of the e-business processes covered by the survey as listed above. The number of factor statements each survey respondent answered depended on the extent of their e-business adoption. Domainspecific factor statements enabled the role of the various factors to be compared across the domains.

The overall response rate was $18.6 \%$, with the response rates increasing with winery size, ranging from $15 \%$ of the small wineries to $46 \%$ of the very large wineries, with more detailed data on the winery sizes and response numbers provided in an earlier paper published in this journal, see [26] for the relevant reference. The research showed that the factors significantly differed in their impact levels across the domains and the impact level was independent of organization size/resource capacity. One implication of this finding is that frameworks of antecedent factors of ebusiness adoption will have greater relevance if they are developed for specific e-business process domains rather than attempting to cover all domains. Thus, influence from powerful stakeholders is not evenly applied across all ebusiness adoption. For example, the government influence is strong with regard to use of e-mail and external web sites, but has negligible impact on the content and strategic focus of winery web sites.

The survey data supported the qualitative evidence presented above that the actions of powerful customers and government influence aspects of winery e-business adoption. The survey evidence relates to the same four observations presented above, and is summarised next in the same order.

\subsubsection{E-government Activity Helps to Drive the Winery's Use of External Web sites}

The quantitative evidence supports the observation that e-government drives some e-business adoption by organizations. The survey showed that almost $90 \%$ of respondents use the web to access wine industry sites regardless of their size, and $80 \%$ of them also access other related government sites, while over $50 \%$ of the exporting wineries process their wine export approvals online and at the time of the survey $22 \%$ of them were also applying for customs clearance through online mechanisms. The likelihood of the wineries accessing the web sites of external organizations significantly increases with size. For example, $72 \%$ of small wineries compared with $100 \%$ of very large wineries accessed government sites with the difference by size significant, $\left(\chi^{2}(3)=11.88, p<.01, N=155\right)$, while for the exporting wineries, approximately $45 \%$ of the small and medium wineries use the online compliance process for wine export approvals compared with approximately $75 \%$ of the large and very large wineries, a significant difference in usage level $\left(\chi^{2}(3)=15.92, p<.01, N=76\right)$. At the time of the survey only $22 \%$ of the exporting wineries applied for customs clearances online, once again this response varied significantly by winery size, ranging from $14 \%$ for small up to $64 \%$ for very large wineries $\left(\chi^{2}(3)=15.79, p<.01, N=31\right)$.

Responses to factor statements related to government influence indicated many respondents recognised the government as an important driver of e-business adoption, with 50\% agreeing that the Government encouraged businesses to use e-mail to communicate with departments, while more than $60 \%$ of respondents either agreed or strongly agreed that government web sites made compliance with regulations easier. Also, over $90 \%$ of wineries agreed that by providing the option to complete wine export approvals online, the government was encouraging increased use of e-business by wineries.

\subsubsection{E-government Activity Potential to Dictate E-business Process Adoption for Compliance Purposes}

The evidence presented next relating to the adoption of online processes in ICS for exports shows that governments can virtually dictate e-business adoption for compliance purposes when they deem this to be in the national interest. Responses to one of the factor statements indicated that regardless of winery size, just over half of all respondents agreed or strongly agreed that most wineries would have to use some e-business processes due to the Australian Government forcing them to do so due to their power to mandate how compliance can occur. Unfortunately the survey was conducted before much training and education for the ICS rollout for exports had been conducted so the level of awareness of this development was varied, with only $25 \%$ of small wineries indicating awareness compared to $75 \%$ of the very large winery respondents.

However, later contact with the Australian Customs Service brought forth a personal communication, dated 1 Aug 2005, from the Minister for Justice and Customs, Senator the Hon. Christopher Ellison, which provided feedback on lodgement numbers for the first ten months after the export component of ICS went live in October 2004, with details in [27]. While adoption of online processes for ICS was not absolutely mandated (a manual process with high overheads was made Available: at custom houses and selected post offices), pressure to complete the clearances using online processes delivered an effective mandate in practice. After only six months, electronic process adoption by all Australian exporting companies was very close to $100 \%$, demonstrating that a high level of adoption success occurred very quickly.

\subsubsection{Powerful Business Customers can Inhibit E-business Adoption by Others}

Powerful business customers can inhibit e-business adoption by their suppliers when it is in their own interests to do so. The survey data supported the qualitative study finding that business customers suppress use of winery B2C sites as a medium for online sales. However, this result varies significantly by winery size, and is strongest for the 
larger wineries who sell to even more powerful supermarket retailers (who in turn own the majority of the bottle shop outlets in Australia). The survey data provided a highly consistent picture of behaviour. For example, only two (18\%) of the very large wineries provide tourist information to promote cellar door sales compared to approximately $70 \%$ of other wineries, with the difference significant $\left(\chi^{2}(3)=13.03, p<.01, \mathrm{~N}=104\right)$, indicating that the very large dominant wineries place little emphasis on selling to individual consumers. As far as online sales go, approximately $65 \%$ of small and medium wineries offer sales online. This figure drops to $35 \%$ for large wineries and drops further again to just $9 \%$ for the very large wineries, and once again these differences are highly significant $\left(\chi^{2}(3)=20.39, p<.01\right.$, $\mathrm{N}=89$ ). Respondents were also asked for the major reason why they chose not to offer online sales, with $46 \%$ indicating it was a low priority, while $25 \%$ acknowledged that it was to avoid conflict with existing business customers.

There is also significant difference in the likelihood of the site including contact details of major distributors and retailers $\left(\chi^{2}(3)=12.17, p<.01, N=82\right)$, with the likelihood increasing as the winery size increases, ranging from $42 \%$ for small wineries up to $91 \%$ for very large wineries. Thus, larger wineries are more likely to use their web site to support existing distribution chains than smaller wineries. When asked if the winery considered the reaction of their distribution chain when deciding on the functionality of their web site, the responses differed significantly by winery size, ranging from $30 \%$ of small up to $80 \%$ of very large wineries. This finding reinforces the message that the powerful business customers have strong influence on the B2C web strategy of winery suppliers. Future research is needed to see if this outcome is specific to wine and wineries, or whether it might also apply to other products and suppliers. Interestingly, when asked if the B2C web site lived up to expectations, significantly more small wineries found that the benefits fell short of expectations than the larger wineries, $\left(\chi^{2}(3)=19.6, p<.01, N=150\right)$, largely because of the disappointing volume of online wine sales delivered for the smaller wineries who had the freedom to choose this option.

\subsubsection{Powerful Business Customers can Promote E-business Adoption by Others}

Powerful business customers can promote e-business adoption by others when it is in their interests to do so. The example in this study is the adoption of the electronic product catalogue system EANnet by wineries as a way of supplying electronic product information at the behest of their customers: 39 respondents indicated 'yes' to this question, with 108 indicating 'no'. There was a significant difference in the 'yes' response by winery size, increasing from $18 \%$ of small to $68 \%$ of the very large wineries $\left(\chi^{2}(3)=14.96, p<.01, N=147\right)$. All of the very large wineries adopting EANnet indicated that the decision to adopt EANnet was driven by the requirements of their major retail customers, whereas this figure was lower for the smaller wineries at just over $50 \%$. The survey supports the interview finding that business customers promote the adoption of EANnet for their own benefit, but this pressure is stronger for the very large wineries compared with the smaller ones because the powerful business customers purchase mainly from the larger wineries.

\section{Findings and Theoretical Implications}

Empirical evidence from both the qualitative interviews and quantitative survey responses shows that some organizations are able to influence the e-business adoptive practices of others. Whether or not this type of influence occurs depends on two important conditions. First, the ability of one organization to influence another depends on their respective power levels - the greater power one organization has over others the greater their leverage when it comes to dictating terms [19]. However, just because an organization is more powerful than another organization is not in itself sufficient reason to exert that power. There must also be a good reason to do so. The organization must perceive there are sufficient benefits that will outweigh the trouble and costs involved in forcing the behaviour of others to change from the status-quo. Also, the e-business process must be one where the network externality effect applies - where the utility for one depends on the number of other users [28]. There is no point in applying power to control adoption rates of others if the number of adopters makes no difference to the delivery of benefits, or if the perceived level of benefits is not worth the costs involved. For example, the government is not concerned with the content and structure of organizations' web sites as these have little relevance to the business of government, nor does the government require everyone to submit tax returns online as the costs of doing so would be prohibitive.

The ICS online processes for managing the control of exports and imports meet the conditions for mandatory adoption due to the government's perception that the benefit for the national good in terms of improved security, accuracy and efficiency outweighs the costs involved, and due to the government's high level of regulatory power. The increased requirement for evidence of identity when exporting (and now also required when importing goods) is a response to the changed security environment with the increased fears of terrorism post the attacks on America on the 11th September 2001. The digital environment can efficiently automate evidence of identity through the use of digital certificates, and thus is far preferred over the manual submission of paper documentation. The imposition of relatively high costs on the manual process, (lodgments can only be made in person at authorized post offices or custom houses, and a $\$ 27.50$ fee is charged for the manual checks of the supplied evidence of identity) has worked effectively to manipulate adoption numbers to close to $100 \%$. The imposition of a mandate can incur high costs. For example, Australian Customs trained nearly 11,500 industry clients on ICS related topics to support the rollout of the export component, and held sessions in all capital cities and many regional centers including all out-ports. Face-toface training is supplemented by online guides and the development of a simulation web site (C Ellison, Minister for 
Justice and Customs, 2005, pers. comm., 1 Aug). Thus, the degree of perceived benefit must be sufficiently high to warrant the costs involved.

However, powerful stakeholder organizations do not always require e-business adopter numbers to rise - the example provided of powerful retailers suppressing the use of the web as an online sales medium for wineries demonstrates that situations arise when the utility for one depends on lowering the number of other users in order to protect a position of competitive advantage. The example of the same powerful retailers requiring wineries to place their product information in the EANnet electronic product catalogue in order for wineries to retain these retailers as customers demonstrates that the same organizations use their power to control adopter numbers in a variety of ways. However, this is only likely to occur when the business customer has sufficient power over the supplier, particularly if the adoption change incurs significant costs. If the costs become too high, then the pressured organization has to evaluate the cost/benefit ratio of maintaining the relationship or staying involved in the same set of operations. Also, firm size can act as a moderating influence on the role of stakeholder power: a firm's size contributes to their position within the industry, which in turn influences the nature of the supply chains which operate at different tiers within the industry. Thus, small organizations are likely not to feel pressure from very large business customer organizations because they do not sell to these powerful customers.

\subsection{A Framework of the Role of Powerful Stakeholders and Control of E-business Adopter Numbers}

This research suggests that the likelihood that one organization (call org p for convenience, with the $p$ denoting powerful) influences the e-business adoption behaviour of other organizations is dependent both on the degree of power difference between org_p and others, and on the extent to which adopter numbers influence benefits for org_p. If org_p's benefits rise as adopter numbers rise or are suppressed, and if org_p has sufficient power, then org_p may elect to exercise that power in order to influence the adoption of e-business processes by others. The empirical evidence presented earlier supports this observation. Org_p is unlikely to wield this power unless there is significant advantage in doing so because of related costs in enforcing compliance and reluctance to cause disadvantage to others without sufficient reason.

Regardless of the extent of the power difference between organizations, if there is minimal benefit in altering the number of adopters of a particular e-business process, then there is a low likelihood that this influence will be brought to bear. As both the power difference and the extent of benefit by changing adopter numbers increases then the likelihood that powerful stakeholders will influence adoption behaviour of others similarly increases. This concept is demonstrated in a simple fashion in Figure 1 so that the general shape of the relationship is easily visualized.

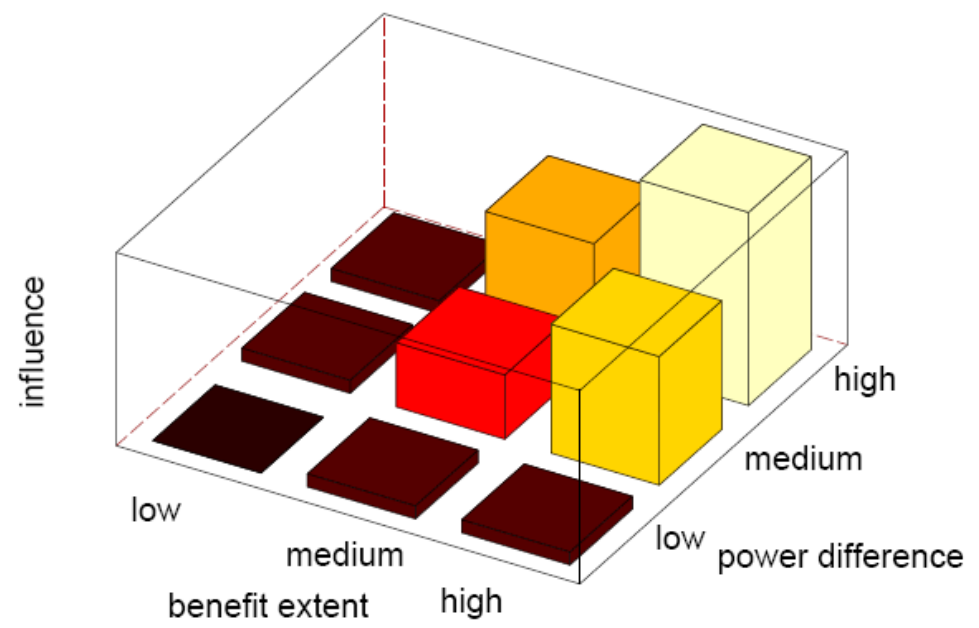

Figure 1: level of influence depends on extent of benefits delivered by the manipulation of adopter numbers and the degree of power difference between organizations

\subsection{Exploring Possible Outcomes Using Game Theory}

Lastly, because strategic games act as a useful model of interactive decision makers [29], the Nash equilibrium from Game Theory is used to explore possible outcomes between powerful and less powerful stakeholders in order to approximate the strategic decision making involved. As a starting point, the following assumptions are made. Powerful organizations can select from the following three actions:

1. Adopt and mandate adoption by others; 
2. Adopt and encourage adoption by others; or

3. Not adopt and do nothing in relation to adoption by others.

Also assume that the implementation costs for the three possible actions increase as follows: the costs for powerful organizations of mandating adoption are greater than the costs of encouraging adoption which in turn are greater than the costs of doing nothing.

Less powerful organizations (call them minor organizations for convenience) have two basic response choices when pressure to adopt is applied: they can either

\section{Adopt; or}

2. Not adopt.

In the case when the powerful organization decides not to proceed, the minor organizations may still decide there is merit in adopting the process for their own advantage, and so the same choices of adopt or not adopt apply. Also assume that the implementation costs for minor organizations of adopting are greater than not adopting. These assumptions provide us with six possible outcomes between the powerful and minor organization players. Next, each possible outcome is ranked from the perspective of each player.

The following ranking scenario is provided to illustrate how the Nash equilibrium might be usefully applied to explore a possible set of actions and responses. Note, these rankings are speculative only, and the fact that a different ranking scenario might produce different outcomes does not detract from the validity of the exercise, but rather indicates that the model is valid regardless of ranking order. From the perspective of the powerful organization, let us assume the six possible outcomes are ranked in preference order from lowest to highest as follows:

1. Adopt and mandate adoption, but minor organizations decide not to adopt - this outcome is the worst as costs are highest and benefits lowest.

2. Not adopt and do nothing, but minor organizations decide to adopt the technology - this outcome is poor as while immediate costs are not incurred, the powerful organization risks being left behind in the long term.

3. Adopt and encourage the adoption, but minor organizations decide not to adopt - this outcome is also poor, as costs are incurred for no benefit.

4. Not adopt and to do nothing, and the minor organizations also do not adopt - this outcome keeps the status quo position.

5. Adopt and encourage the adoption, and some minor organizations decide to adopt - this outcome is better as increased benefit (e.g. improved efficiency) is delivered for a medium level of cost, but may not maximize potential benefits.

6. Adopt and mandate the adoption, and all or most of the minor organizations decide to adopt - this outcome is the best as the benefits from adoption are assumed to outweigh the immediate costs and the benefits are maximized.

From the perspective of the minor organizations, let us assume the outcomes are ranked in preference order from lowest to highest from the perspective of the minor organizations. The ranking numbers use roman numerals to distinguish them from those of the powerful organization.

i Decide to not adopt in response to a mandate - this outcome is the worst as while no costs are incurred, the organization is left out of the altered mainstream action.

ii Decide to not adopt in response to encouragement to adopt - this outcome is poor as while there are no costs, the status-quo position is unlikely to remain the same and the relationship with the powerful customer will suffer.

iii Decide to adopt when the more powerful organization is not adopting - this outcome incurs costs while the relationship with the powerful organization is unchanged, so the benefits from adoption run the risk of being low.

iv Decide to not adopt in keeping with the powerful organization's decision to not adopt - this outcome incurs no costs but no progress is made and opportunities are likely to be missed. 
$\checkmark$ Decide to adopt in response to a mandate - this outcome is better as while costs are incurred, progress is made, and the relationship is maintained - if the mandate is successful then the competition with other minors will not vary by much.

vi Decide to adopt in response to encouragement to adopt - this outcome is the best as while costs are incurred, progress is made, and the relationship with the powerful organization is likely to be enhanced assuming that fewer minors will choose to adopt than if faced with a mandate.

Next, these preferences are placed into a game matrix, and then the best response from minor organizations for the three possible actions by the more powerful organization of mandate (prefer v over i), encourage (prefer vi over ii) or not adopt (prefer iv over iii); and the best response from the powerful organizations for the two possible actions by the less powerful or minor organizations of adopt (prefer 6 over 5 or 2) or not adopt (prefer 4 over 3 or 1 ) are highlighted with an * character, shown in Figure 2. Nash equilibria represent "a stable "social norm": if everyone else adheres to it, then no individual wishes to deviate from it" [29], p. 22. The Nash equilibria, or stable states, are those outcomes with two *'s, marking them as the best response from the perspectives of both players; these are circled in Figure 2.

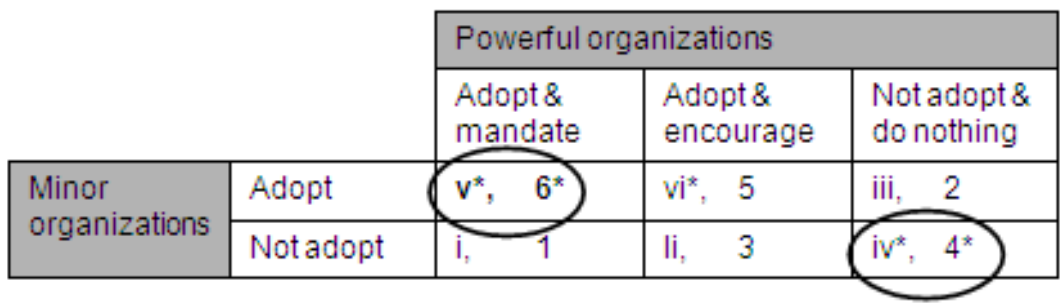

Figure 2: Game matrix of ranked preferences for adoption responses to influence from powerful stakeholders with regard to adoption of e-business

From the results displayed in Figure 2 and based on the assumptions provided, one would expect to see either of the circled outcomes. Note also that the stable state outcomes are not sensitive to the ordering of the three lowest preference rankings of the powerful organizations, nor are they sensitive to the ordering of the three highest preference rankings of the minor organizations. If the assumptions made here correspond roughly to reality, then it is reasonable to suppose that minor organizations are more likely to adopt e-business processes in response to pressure to adopt from more powerful organizations than not, and are more likely not to adopt if pressure from more powerful organizations is absent. These Game Theory outcomes, based on the assumed rankings as described above, support the theory developed here that powerful stakeholders control e-business adopter numbers when there is sufficient advantage for them to do so.

\section{Conclusions}

Organizations are not always free to determine their own e-business strategies. These strategies will not always be guided by the perception of relative advantage and influenced by the availability of resources to enable implementation and on-going maintenance. This research shows that, for some areas of e-business adoption, neither perceived benefits nor resource capability determine the adoption decision, but rather this decision is largely determined by the actions and wishes of a more powerful external stakeholder. Less powerful organizations sometimes choose to adopt an e-business process that strategically may make little difference to their own business bottom-line, and which may consume resources they would rather use elsewhere, simply in order to "stay in the game". Powerful organizations such as governments and big business customers have a greater say in the rules of engagement and can therefore encourage and even dictate e-business adoption when it is in their own interests to do so. Analyzing adoption behaviour using a Game Theory approach aids in understanding the array of choices between actions and responses faced by organizations.

\section{Acknowledgments}

I would like to gratefully acknowledge the support of Professor Edmund Fitzgerald and Professor Mark Toleman during the research of e-business adoption by Australian wineries, and the advice of Professor Tony Roberts with regard to Game Theory.

\section{References}

[1] S. R. Clegg, Frameworks of Power. London: Sage Publications Ltd, 1989.

[2] P. K. Dutta, Strategies and Games: Theory and Practice. Cambridge, Massachusetts: The MIT Press, 1999.

[3] S. R. Clegg, D. Courpasson, and N. Phillips, Power and Organizations. London: Sage Publications Ltd, 2006. 
[4] A. M. Brandenburger and B. J. Nalebuff, The Right Game: Use Game Theory to Shape Strategy, Harvard Business Review, vol. 73, pp. 57-71, 2000.

[5] S. Nwankwo and B. Richardson, Organizational leaders as political strategists: a stakeholder management perspective, Management Decision, vol. 34, pp. 43-49, 1996.

[6] A. D. Sanchez, C. E. Koh, L. A. Kappelman, and V. R. Prybutok, The relationship between IT for communication and e-government barriers, presented at Ninth Americas Conference on Information Systems, Tampa, Florida USA, 2003.

[7] W. Golden, M. Hughes, and M. Scott, The role of process evolution in achieving citizen centred e-government, presented at Ninth Americas Conference on Information Systems, Tampa, Florida USA, 2003.

[8] D. Gefen, P. Pavlou, M. Warkentin, and G. Rose, EGovernment Adoption, presented at Eighth Americas Conference on Information Systems, Dallas, Texas, 2002.

[9] E. S. Dunt and I. R. Harper, E-Commerce and the Australian Economy, The Economic Record, vol. 78, pp. 327342, 2002.

[10] OECD, The economic social impact of electronic commerce - preliminary findings and research agenda, Paris 1999.

[11] Australian Government Department of Communications Information Technology and the Arts, (2004), Australia's Strategic Framework for the Information Economy 2004-2006, [Online]. Available: http://www.dbcde.gov.au/ data/assets/pdf file/0018/20457/New SFIE July 2004 final.pdf

[12] Australian Government Information Management Office, (2006), e-Government Strategy: Responsive Government - A New Service Agenda, [Online]. Available: http://www.agimo.gov.au/ data/assets/pdf file/0010/ 51499/e-gov strategy.pdf

[13] NOIE, (2003), E-government Benefits Study, [Online]. Available: http://www.agimo.gov.au/publications/2003/03/ e-govt benefits study

[14] W. Ke and K. K. Wei, Successful e-government in Singapore, Communications of the ACM, vol. 47, pp. 95-99, 2004.

[15] C. Christensen and J. Bower, Customer power, strategic investment, and the failure of the leading firms, Strategic Management Journal, vol. 17, pp. 197-218, 1996

[16] F. Wu, V. Mahajan, and S. Balasubramanian, An analysis of e-business adoption and its impact on business performance, Journal of the Academy of Marketing Science, vol. 31, pp. 425-447, 2003.

[17] T. J. Chen, The Diffusion and Impacts of the Internet and E-Commerce in Taiwan., I-Ways, vol. 26, pp. 185-193, 2003.

[18] J. Gibbs, K. L. Kraemer, and J. Dedrick, Environment and Policy Factors Shaping Global E-Commerce Diffusion: A Cross-Country Comparison., Information Society, vol. 19, pp. 5-18, 2003.

[19] A. Cox, The art of the possible: relationship management in power regimes and supply chains, Supply Chain Management: An International Journal, vol. 9, pp. 346-56, 2004.

[20] A. Cox, G. Watson, C. Lonsdale, and J. Sanderson, Managing appropriately in power regimes: relationship and performance management in 12 supply chain cases, Supply Chain Management: An International Journal, vol. 9 , pp. 357-71, 2004.

[21] AWBC, (2007), Australian Wine and Brandy Corporation Wine Law, [Online]. Available: http://www.awbc.com.au/Content.aspx?p=17

[22] AWBC, (2007 January), Flow chart of wine sector organisations, [Online]. Available: http://www.awbc.com.au/ library/flowchartofIndOrgs.pdf

[23] Winetitles, The Australian and New Zealand Wine Industry Directory, 21st ed. Adelaide: Winetitles, 2003.

[24] Winetitles, (2003), Australian Wine Industry Overview, [Online]. Available: http://www.winetitles.com.au/awol/ overview/wineries.asp

[25] National Supply Chain Reform Task Force, (2004), EANnet, [Online]. Available: http://www.healthsupply chain.gov.au/summit04/reports/EANnet.pdf

[26] B. Roberts and M. Toleman, One-size e-business adoption model does not fit all, Journal of Theoretical and Applied Electronic Commerce Research, vol. 2, pp. 49-61, 2007.

[27] B. Roberts and M. Toleman, The Role of Government in E-Business Adoption, in Global E-Government: Theory, Applications and Benchmarking, L. Al-Hakim, Ed., 1st ed. Hershey, PA, USA: Idea Group Inc, 2007, pp. 64-85.

[28] H. R. Varian, Intermediate Microeconomics. New York: W.W. Norton \& Company, 1999.

[29] M. J. Osborne, An introduction to game theory. Oxford: Oxford University Press, 2002. 